All letters are subject to editing and may be shortened. Letters should be sent to the BJGP office by e-mail in the first instance, addressed to

journal@rcgp.org.uk (please include your postal address). Alternatively, they may be sent by post as an MS Word or plain text version on CD or DVD. We regret that we cannot notify authors regarding publication. Letters not published in the Journal may be posted online on our Discussion Forum. For instructions please visit: http://www.rcgp.org.uk/bjgp-discuss

\section{Learning disability}

It is quite natural that key experiences from our family life show transference to our professional relationships. I certainly draw on personal feelings from childhood to aid empathy for children receiving health care. However, such anecdotal recollections ${ }^{1}$ can give an unreliable picture of general systems, such as primary medical care for people with learning disabilities, across Britain.

Inequalities in GPs' involvement with these patients were first drawn to my attention while collecting 1-month diaries of patient contacts from $40 \mathrm{GPs}$, for the ICD-10 primary health care field trial. ${ }^{2}$ Most GPs saw no people with learning disabilities (code F70) in that month, although a minority had several patients (mean 0.28 cases per month). ${ }^{3}$ Based on population prevalence, one would expect about one case per day. About the same time, we found that the women with learning disabilities living in the community who managed to see their GP (for a cervical smear) often had unhappy experiences that they were reluctant to

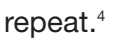

Fitzpatrick ${ }^{1}$ is off target comparing this problem to prejudice like racism (marked by xenophobic fear or hatred): a decade's primary care research has confirmed that indifference really is the problem, with most of the population with disabilities invisible to clinicians. We found staff in schools very open to assessing and checking the health needs associated with learning disabilities, when the 'health facilitation' proposed by the Department of Health was introduced. ${ }^{5}$ A minority of GPs responded very positively when we tried to introduce health facilitation to general practice. ${ }^{6}$ Their patients (in varied settings) gained individual Health Action Plans, including development of some quite new services. Sadly, a substantial majority of GPs were not interested in the local residents with learning disabilities, let alone prepared to initiate seeing those patients annually.

Such indifference is not just found frequently in medical practice. It is also common in our academic ivory towers. ${ }^{7}$

\section{Woody Caan,}

Department of Child \& Family Health, Anglia Ruskin University, Cambridge.

E-mail: woody.caan@anglia.ac.uk

\section{REFERENCES}

1. Fitzpatrick M. Learning difficulties scandal. Br J Gen Pract 2008; 58(557): 899 .

2. Ustun TB, Goldberg D, Cooper J, et al. New classification for mental disorders with management guidelines for use in primary care: ICD-10 PHC chapter five. Br J Gen Pract 1995; 45(393): 211-215.

3. Caan W, Hampton-Matthews S. One from the heart for people with a learning disability. Br J Nurs 1999; 8(2): 97-100.

4. Broughton S, Thomson K. Women with learning disabilities: risk behaviours and experiences of the cervical smear test. J Adv Nurs 2000; 32(4): 905-912.

5. Caan W, Lutchmiah J, Thomson K, Toocaram J. Health facilitation in primary care. Prim Health Care Res Dev 2005; 6: 348-356.

6. Thomson K, Gripton J, Lutchmiah J, Caan W. Health facilitation in primary care seen from practice and education. Br J Nurs 2007; 16(18): 1156-1160

7. Caan W. Shame on the academic community too. Lancet 2008; 372(9647): 1384.

DOI: 10.3399/bjgp09X419556

\section{Author's response}

The parallel between racial prejudice and the treatment of people with learning disabilities is not mine but the central theme of the 2007 Mencap report which blames 'institutional discrimination' in the NHS for the deaths of six patients. This concept was adopted from the 1999
Macpherson report which attributed the failure to prosecute the killers of Stephen Lawrence to 'institutional discrimination' within the Metropolitan Police. Although there is a long history of racial discrimination in Britain, it is doubtful whether this remains a significant force now that 'anti-racism' has become the official ideology leading to extensive police activity on the streets, on the football terraces, and in workplaces.

No doubt people with learning disabilities, like many other people, suffer from neglect and sub-standard treatment in the NHS. What I doubt is whether they suffer from systematic discrimination, and I dispute the value of trying to tackle the specific problems they face by promoting this posture of victimhood and grievance.

It is not surprising that people who have difficulties in articulating their demands experience difficulties in gaining access to general practice: traditionally a demand-led service. There are real problems in providing satisfactory medical care for people with learning difficulties - including the mediating role of family and professional carers - but these are not improved by the sort of posturing and token gestures (like annual health checks) currently being introduced.

\section{Mike Fitzpatrick,}

Barton House Health Centre, 233 Albion Road, London N16 9JT. E-mail: fitz@easynet.co.uk

DOI: 10.3399/bjgp09X419565

\section{Usual care in back pain trials}

In the November issue of the BJGP, 